\title{
Task-based interaction and incidental vocabulary learning: a case study
}

\author{
Jonathan Newton Victoria University of Wellington
}

\begin{abstract}
This case study examines the vocabulary gains made by an adult learner of English as a second language as a result of performing four communication tasks. Gains were measured on comparisons of pre- and post-tests of vocabulary from the worksheets from the four tasks. These gains are discussed in relation to the interactional processes involving unfamiliar vocabulary. Explicit negotiation of word meaning appeared less deterministic of post-test improvements than use of words in the process of completing the task. While this result may to some extent be an artifact of test design, it is also true that when the group actively used vocabulary which was unfamiliar to the subject of this study, the embedding of this vocabulary in the context of the task and its interactive use are likely to have provided not only important information about word meaning but also the conditions whereby that meaning could be acquired. The placement of a word on task worksheets and the nature of a task, whether a split information task or a shared information task, both had a strong effect on use and acquisition of new vocabulary.
\end{abstract}

\section{Introduction}

This article argues that use of and exposure to vocabulary from the worksheets for communication tasks provide language learners with important opportunities for text-based vocabulary learning. This is in addition to the generally accepted role of these tasks in developing fluency. To support this claim, the article presents a case study of an adult ESOL learner, whom we will call Chang, and his experience of confronting new vocabulary when doing communication tasks. Instances of both his acquiring and failure to acquire new vocabulary are discussed in relation to the interactive processes which he was exposed to and participated in.

\section{Background}

Evidence of incidental vocabulary learning through communication has been shown in studies by Elley (1989), Simcock (1993) and Joe (1994). Elley (1989) provides evidence of incidental vocabulary

Address for correspondence: English Language Institute, Victoria University of Wellington, PO Box 600 , Wellington, New Zealand. 
learning for 7-8-year-olds involved in listening to stories in which there was repetition of the new words, illustrations of the words and redundancy through context. Elley recorded gains of $15 \%$ where there was no explanation of the new words and $40 \%$ gains where explanation occurred. While this result relates largely to listening, it also shows the acquisition of vocabulary in a context where attention to a text is on meaningful communication and not on language itself.

Simcock (1990) studied learners' performance in ask-and-answer activities where students read a story in pairs and then responded to preset questions from their partners about the events in the story, responding as if they were the people in the story who had experienced these events. She found that new vocabulary encountered in the text for the activity was used productively and accurately by learners even when they were not being asked about these items by their partners. This suggests that incidental vocabulary learning takes place even when a learner's focus is primarily on meaningful performance of a communicative activity.

Joe (1994) investigated the effects of the read and retell technique on vocabulary learning. In her study, adult ESL learners in two experimental groups read a story and retold it individually, learners in one group retelling with the text and other without. Learners from both groups were tested on words from the story before and after the activity. Learners in a control group did only the test on the words. Predictably, Joe found that learners who performed the read and retell task could recognize and define more accurately and fully the meaning of vocabulary from the story. But more interestingly, the learners who made the greatest improvement in the post-test were those who used the story vocabulary more generatively (that is, in new contexts and in new structures) in the retelling (see also Joe's article in this volume).

While the studies above deal with prose texts, there is also evidence of vocabulary learning through communication task work. In a study of the acquisition of mathematical vocabulary through the performance of split information activities by 11-13-year-old students, Hall (1992) found that the vocabulary learning of students working on these interactive activities was greater than that of students working within a teacher-fronted arrangement with a reading focus. Hall concluded that split information activities provide opportunities for talk which increase both language knowledge and content knowledge.

A key issue with all these studies is: to what processes can we attribute the learning that occurred? Elley claims that repeated exposure to new vocabulary in a meaningful context accounted for the vocabulary gains for his subjects. Both Joe and Hall stress the 
importance of generative use of vocabulary as a mark of deep processing of content which facilitates learning. This study discusses the role of another process, the negotiation of meaning, in vocabulary acquisition. Negotiation, the process of resolving communication breakdowns, has received a great deal of attention in SLA literature. It is seen as a key resource for making language input (i.e., unfamiliar vocabulary) comprehensible (Long, 1981; 1983; Pica et al., 1987) and for providing a vehicle for feedback on language production (Swain, 1985, Pica et al., 1989; Ellis, 1991). By presenting either a correct model of a prior utterance or simply an expression of noncomprehension, feedback on production offers learners the chance to restructure their interlanguage, to test out the proximity of this restructuring to the target forms and thus to precipitate language change. Studies concerning the role of task-based interaction and SLA are numerous and need not be rehearsed here (see Long, 1989; Ellis, 1991, for useful reviews of research on task-based interaction and SLA). Negotiation is closely associated with the use of classroom communication tasks and in this article the two are brought together through the study of incidental vocabulary learning.

\section{Method}

\section{The subject}

Chang, a 21-year-old Taiwanese male, was a recent immigrant to New Zealand, where he was about to embark on an undergraduate degree in economics. He was chosen because his pretest knowledge of task vocabulary was the lowest of eight learners from the class who were used in a larger study. Chang was a rather dominant interlocutor in his group. Despite having the lowest pretest vocabulary score, he nevertheless took an average of $40 \%$ of talk and $40 \%$ of negotiating questions (373 out of 945) across the four tasks.

\section{The study}

Chang's class, divided into groups of four, did six communication tasks over a period of eight days. Four of these tasks (see Appendix) were analysed for this study. Two of the tasks were twoway or split information tasks in which interlocutors were required to exchange information in order to complete their worksheets. The other two tasks were shared - information tasks in which the participants were required to solve a problem by consensus. The topics of these tasks paralleled those of the two split tasks.

In task 1, the students were given information about six patients 
on a heart-transplant waiting-list. A heart has become available for a transplant operation, and the students have to decide which of the six people should be given a new heart. In task 2 , students are given information about a zoo. The layout of the zoo is no longer appropriate, and new developments mean that a new layout must be implemented. Students are asked to design a new layout, and show how their designs solve the current problems of the zoo. In task 3, each student is given partial information about four patients and two criteria which determine priority for treatment. The group has to assemble all the information and then use the criteria to decide which patient receives the treatment. In task 4, each student has partial information about the layout of a zoo. The group has to assemble all the information into a single plan, and then describe the location of a set of symbols printed on the plans.

To assess Chang's knowledge of vocabulary from the tasks, he, along with the class, did a vocabulary pretest of the 111 main content words from the task worksheets. In the test, the learners were asked to identify the words set out in a list by providing either translations, definitions, pictures, paraphrases or examples. While not a particularly rigorous form of testing, it had the advantage of not exposing learners to additional information about the words prior to the tasks. The same test was presented three days after the tasks had been performed as a post-test measure. None of the words was glossed in the worksheets for the tasks, and dictionaries were not permitted. Only on three occasions in the tasks did the supervisor give help with a difficult word.

All groups were audiorecorded; two groups, Chang's included, were also videorecorded.

\section{Questions}

The search for meaningful connections between Chang's exposure to and work with new vocabulary in interaction, and subsequent post-test improvements, was motivated by a series of questions which were as follows:

1) Did Chang's knowledge of task vocabulary improve as a result of doing the tasks? If so, by how much?

2) Was explicit clarification of the meaning of unfamiliar vocabulary through negotiation necessary for acquisition of this vocabulary?

3) Did the type of task influence the amount of words that Chang learnt? 
4) Was Chang's active involvement in initiating and/or using new vocabulary necessary for acquisition?

\section{Results and discussion}

\section{Chang's prior knowledge of task vocabulary}

In the pretest of task-sheet vocabulary, Chang was able to display knowledge of 55 of the 111 words tested. This left 56 words which were apparently unknown. Across the four tasks this represents an average of 14 or so words per task. While other learners in his group knew more of the task vocabulary, only 38 of the 111 words were known by all members of the group in the pretest. Some 61 words were known by at least one member of the group, but not known by at least one other. The remaining 12 words were not recognized by any members of the group. Although we would expect unfamiliar words to make successful task completion difficult, all tasks were completed with a high degree of accuracy and within the time limit.

\section{Evidence of vocabulary acquisition}

The post-test results are presented in Table 1 where they are crosstabulated with an analysis of use of the words in the tasks. Chang made gains for 21 of the 56 words which he had not recognized on the pretest. This is an improvement of about five to six words per half an hour of communicative task work. While Chang could no doubt learn many more words in half an hour of solid vocabulary study, it must be remembered that here vocabulary learning was incidental to the main goal of the activity. This is encouraging for teachers and for learners. Chang's acquisition of new vocabulary took place in a meaningful communicative context in which there was minimal teacher input and direction apart from providing the task, and no use of dictionaries or vocabulary glosses. The two main sources of help with new vocabulary were therefore the context of the task and knowledge of non-native speaker interlocutors.

\section{Use and acquisition}

With two exceptions, Chang only acquired new words from the worksheets that had been used in interaction. Clearly, hearing or using unfamiliar words in pursuit of a meaningful and contextually defined purpose encouraged Chang to process task vocabulary sufficiently for words to be acquired. 
Table 1 The relationships between Chang's post-test results and the group's use of vocabulary which Chang had not recognized on the pretest $(n=56)$

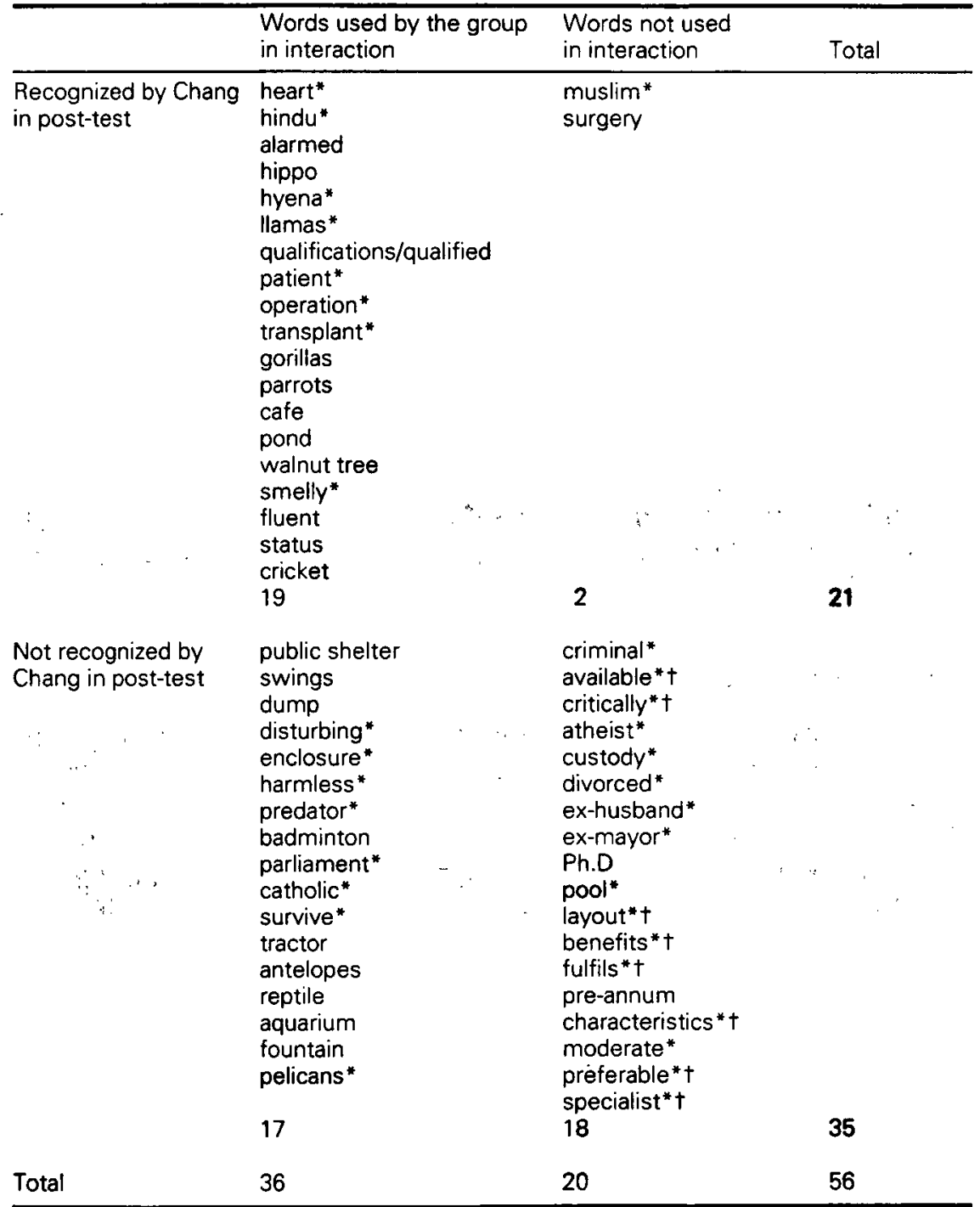

Notes:

$*$ = from the shared information tasks.

$t=$ from the instructions or introductory sections.

The corollary is that with the same two exceptions, words that were not used in interaction were not acquired by Chang. Without use by either himself or an interlocutor there was no guarantee that Chang would pay attention to a word and therefore little opportunity for the word to be acquired. 
But why were so many of the unfamiliar words that were used (and, indeed, used by Chang) not acquired by him in the process? Why, also, was such a large number of words from the worksheets not used at all? What was it about these words that discouraged their use? Possible answers lie in the position of the words in the tasks; the types of tasks; and the constraints of face-to-face interaction.

Almost half (8 out of 18) of the unused words which Chang did not learn were from either the instructions or introductory information sections of the tasks. These words are marked by ' $\dagger$ ' in Table 1. This was not information that Chang was expected to discuss directly, let alone study at any depth. In fact the tasks were introduced orally by the supervisors, making much of the written information in these sections superfluous. It is not surprising, then, that none of the instructional vocabulary was used in interaction, and was not acquired by Chang.

Of the remaining ten unused words which Chang did not acquire and which were not from the instructions, eight were from the shared tasks and only two from the split tasks. The influence of task type on Chang's dealings with task vocabulary is complex. The shared tasks offered Chang both greater freedom to participate and to be selective in the information he discussed. This shows in the predominance of shared task-content vocabulary in the unused category. At the same time, however, the problem-solving goals of the shared tasks required meaningful dealings with worksheet vocabulary. This we see in the following example where Chang (S1) and his group struggle to find the meaning of the phrase "All the enclosures should be filled':

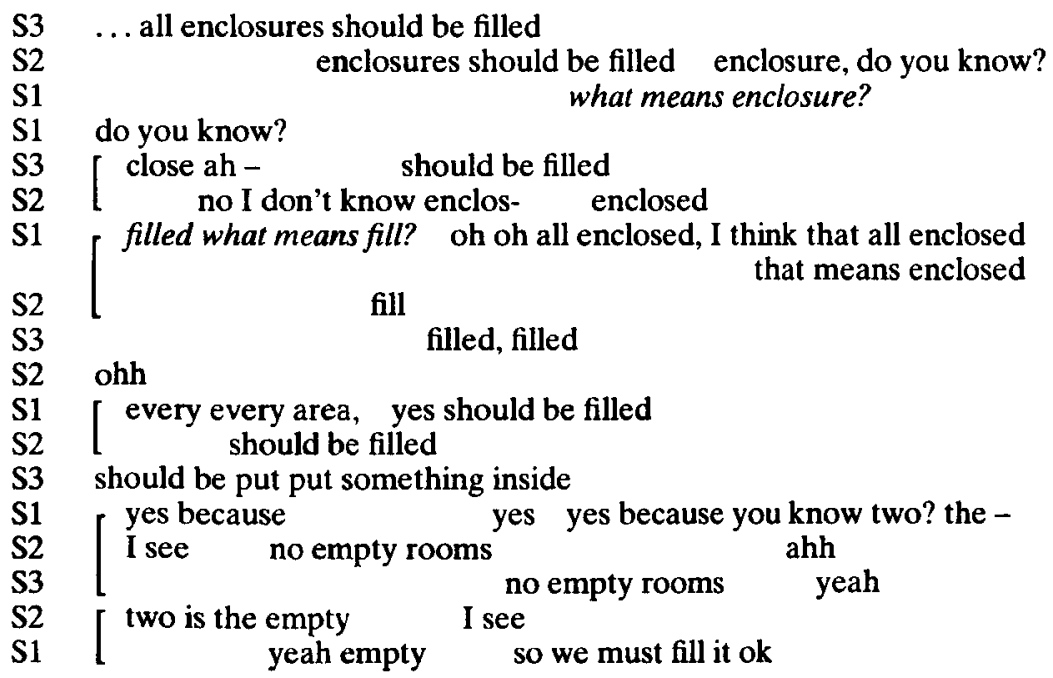


The split tasks, on the other hand, obliged the group to use all the content vocabulary to complete the task, although often without any requirement to deal meaningfully with this vocabulary. The following example is typical of the kind of negotiation that Chang engaged in over words in the split tasks. Here, the word reptiles, which Chang did not know in the pretest or post-test, is used repeatedly by Chang and other interlocutors, and yet without Chang apparently knowing what the word meant. In fact he simply resorts to spelling it out as he is also unsure how to pronounce the word. The task after all only required that Chang tell the group where the place named 'reptiles' was located in the zoo:

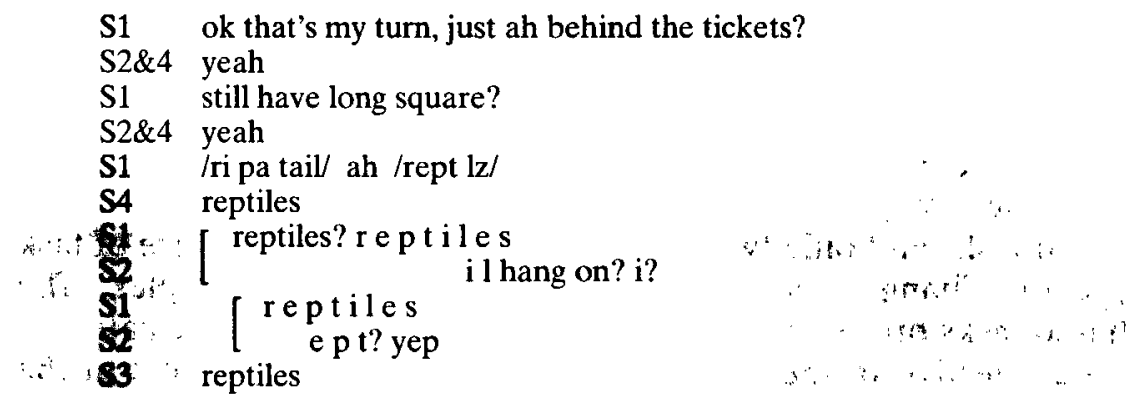

\section{Processing constraints and the task-essentialness of words}

Overall, Chang's nonuse and nonacquisition of certain words can be attributed to the processing constraints and rationalization of attention necessary in face-to-face communication. Because of these, Chang was likely to use and pay attention only to those resources he needed in order to reach his communicative goal. To reach such a goal, some items in the task worksheets will be more essential than others. The task-essentialness of lexical and grammatical resources appeared to vary depending on the type of task and the placement and role of given items in a task. This point is discussed at length by Loschky and Bley-Vroman (1990) in respect of grammatical structures but the same arguments also apply to vocabulary. Not only did Chang choose to ignore certain vocabulary but the variability of the gains in the post-test suggest that some words were processed more deeply than others, depending on how essential the words were, and what they contributed to the task. Chang's processing of reptile in the example above is extremely shallow, and contrasts markedly with his processing of transplant in the example below. 
This word is an obvious example of an essential item in the shared medical task which required or inspired deep processing. The word occurs three times in the worksheet in very explicit contexts such as '... six patients badly need a heart transplant operation'. While not explicitly clarified for meaning during interaction, it nevertheless receives considerable attention in the following exchange:

S1 first one ah not good likely to survive only two or more years if the heart transplant is successful, huh?, if it successful still only two or more years? that means that?

S2,3\&4 yeah, yeah, yes

S1 if, if, it failed then die suddenly, will die

S3 maybe only survives only two more years, so after that, ah, he will die -

$\dddot{\text { S2 }}$ - because they said he likely, he is likely to survive only two more years if the heart transplant? is successful

S4 is not important you mean?

S1 yeah what's the meaning?

S2 ahh?

S4 your meaning, is not important for you?

S2 yeah

S1 what's the sentence mean?

S3 patient A you mean?

S2 [ oh so if if the heart trans, transplant? is successful he only he

$\mathrm{S} 1$

S4 yes only live two more years

Not surprisingly, transplant registers an improved score on the posttest.

\section{Use, negotiation and interlocutor roles}

To this point, the discussion, based on Table 1, has related post-test outcomes to a single process dichotomy - whether words were used or not used interactively. But the fact that Chang failed to acquire almost half the words that were used in interaction also deserves closer investigation. To understand what factors determined whether Chang did or did not learn a word, I have analysed a number of the interactional processes associated with these words: the number of times each word was used, whether or not it was negotiated for meaning, the accuracy of information provided through negotiation and, finally, Chang's role in both negotiation and use of the words. Table 2 presents a crosstabulation of the post-test results with an analysis of these interaction processes. 


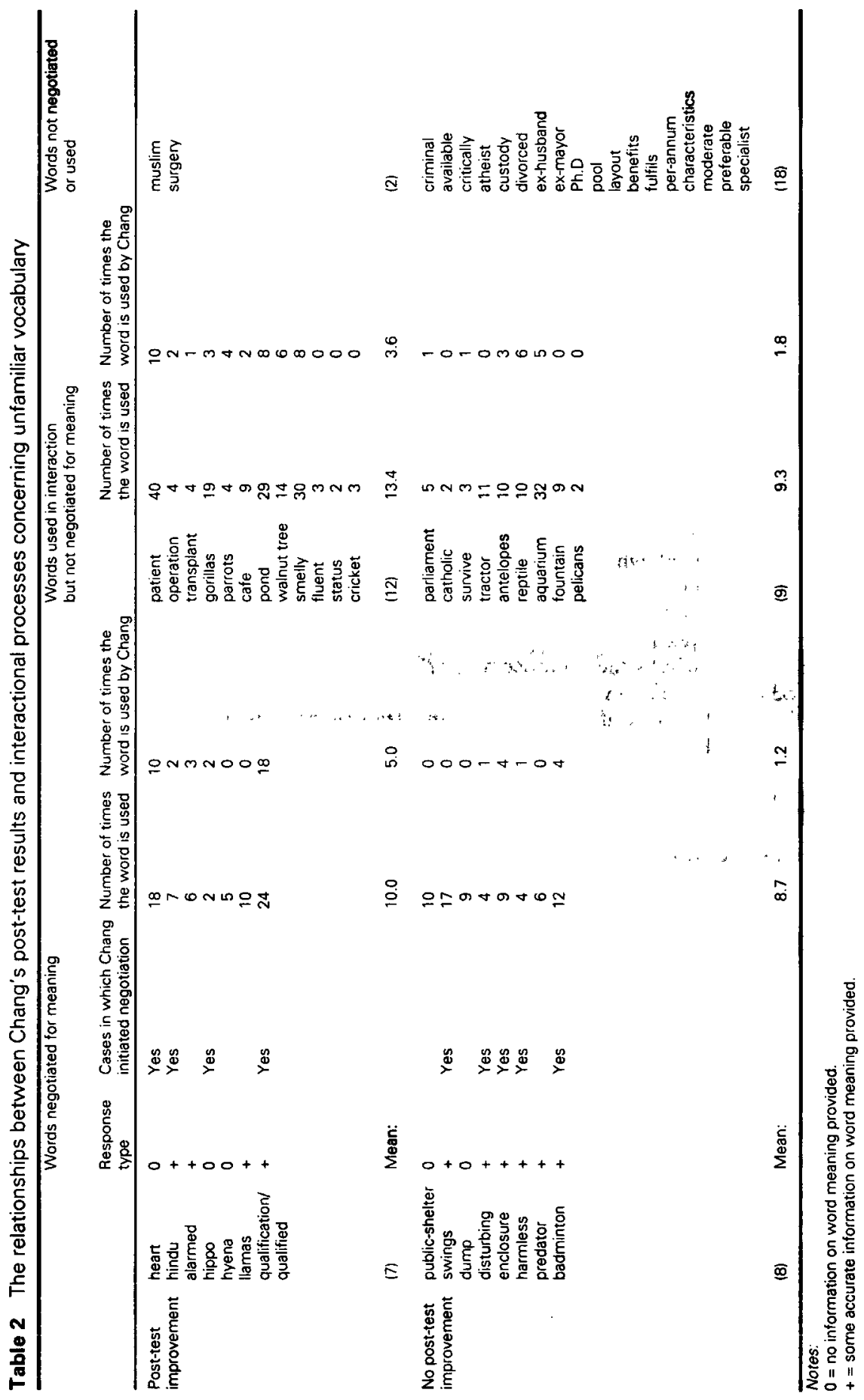


The picture presented in Table 2 is far from straightforward. Perhaps most surprising is the fact that negotiation, the means by which a word receives the most explicit and concentrated degree of attention, appeared to have less affect on Chang's acquisition of new vocabulary knowledge than non-negotiated use of the word in interaction. Even when Chang explicitly requests clarification of word meaning and receives accurate and informative responses, his knowledge of these words does not always improve in the post-test. In fact, Chang failed to show post-test improvement for five out of the seven words accurately negotiated at his request.

In contrast, when the patterns of use were averaged, a consistent, if not robust pattern emerges: words that Chang was able to recognize on the post-test are used more frequently in interaction than words for which he showed no post-test improvement. This pattern reinforces the trend seen in Table 1 in which words from the worksheets were almost certainly not acquired if not used.

But this still leaves the question of why so many words that Chang himself used as well as words that were successfully negotiated, failed to show post-test improvement. One reason discussed above was Chang's need to meet communicative goals. This necessarily limited the processing time available for pursuing conscious learning of new items beyond what was required to move the task forward. Other reasons lie in the multiple interaction of learnerinternal factors, word-specific linguistic factors, and interactional factors. While attempting to deal with the complexity of this interaction lies beyond the scope of this study, one factor that warrants further discussion is the sensitivity of the test instrument to Chang's pre-existing knowledge or recognition of vocabulary.

\section{The testing instrument}

Since the test required Chang to display productive knowledge in some way, it failed to account for receptive knowledge or even the sense of 'I don't know this word, but I have seen it before'. In such cases, of course, seeing and hearing the word in a specific context may be enough to trigger and strengthen recall of the previous experience with that word.

Equally, while seeing and hearing new words may have been enough temporarily to imprint a word in Chang's short-term memory sufficient for the task, it will often by insufficient to transfer the word to longer-term memory storage. With hindsight, the testing instruments could have been improved in a number of ways. First, we could ask the learners to show they have acquired further proof of deeper knowledge in a second step. Secondly, the tests for the 
study were done in silence except where a request was made by a subject to hear a word. In effect this was using a written test to measure the effects of what was often spoken exposure to the word. To overcome this, words from the test could be read aloud as learners read them. Learners could also either respond in writing and/or by thinking aloud with an audiorecording made of the sessions. In the case of spoken responses, tests could be administered either separately to each individual, or in a language laboratory with separate recording facilities for each subject. Thirdly, to obtain further information, learners could review the words after the post-test and introspect on questions such as whether they remembered particular words in the tasks, what help they received from other learners with unfamiliar words and what strategies they used when they encountered unfamiliar words while working on the tasks.

\section{Summary}

By matching the post-test vocabulary gains of a single learner, Chang, against interactional uses of worksheet vocabulary from communication tasks, this study has provided evidence of incidental vocabulary acquisition through communication tasks. Chang made post-test gains for 21 words from the four tasks he performed. All but two of these words had been used in interaction while, with the same two exceptions, worksheet vocabulary that was not used in interaction was not acquired by Chang. But whether Chang or others accurately negotiated a word, and whether Chang himself was involved in using a word, did not lead to a greater chance of that word being acquired than if it was simply used by the group. There was therefore little evidence to show that negotiation of word meaning, and even successful negotiation prompted by Chang, had a strong impact on the particular words that Chang acquired. However, it is not necessarily the case that negotiation was of no use; it may, for example, have only been used in the case of more problematic words which in turn were more difficult to acquire anyway. Clearly there were a multitude of factors which determined the likelihood of Chang acquiring any given unfamiliar word. The effect of two of these factors, the placement of a word in the worksheet and the type of task, were discussed. Most of the unfamiliar words which Chang did not use and did not acquire were located either in the instructions for the tasks or appeared in the shared tasks. In the latter case, the greater freedom to participate in these tasks clearly allowed Chang and his group simply to avoid certain words without this affecting their successful completion of the task. Thus whether Chang and other members of his group perceived task vocabulary 
as superfluous, useful or essential (Loschky and Bley-Vroman, 1990) was determined to an extent by vocabulary placement and by the type of task.

Finally, the testing instrument was not sensitive to either partial knowledge of words in the pre- and post-tests or to partial learning in the activity. More information on this variable would help explain the results obtained.

\section{Conclusion}

Observing learning is difficult. Even in a case study such as this in which we can examine processes and outcomes in some detail, our investigation is limited to observable processes and their apparent relationship to observable outcomes. Perhaps the value of a case study, though, is that it makes us aware of the complexity of variables that affect learning, a complexity which is easily overlooked in the averaging effects of larger studies. While this study provides important evidence of a learner incidentally acquiring a substantial amount of unfamiliar vocabulary from a communication task, the results throw up as many questions as they answer. In this, the study opens the way for similar small-scale replications which build on the methodology and reveal more of the relationship among learner, linguistic and interactional variables, on the one hand, and learning outcomes on the other. For further studies, two needs are immediately apparent. First, such studies would benefit from retrospective or concurrent information from learners on the internal processes that parallel those which we observe in group interaction. Secondly, as discussed above, there is a need to develop instruments which are more sensitive to degrees of acquisition and to both receptive and productive vocabulary knowledge. Developments in both these areas would, I believe, add greatly to the insights possible from a study such as this.

\section{References}

Elley, W. 1989: Vocabulary acquisition from listening to stories. Reading Research Quarterly 24, 174-87.

Ellis, R. 1991: The interaction hypotheses: a critical evaluation. In Sadtono, editor, Language acquisition and the second/foreign language classroom. Anthology Series 29. Singapore: SEAMEO RELC.

Hall, S. 1991: Using split information tasks to learn mathematics vocabulary. Guidelines 14, 72-77.

Joe, A. 1994: The effect of text-based tasks on incidental vocabulary learning. Unpublished MA thesis, Victoria University of Wellington. 


\section{Task-based interaction and incidental vocabulary learning}

Long, M. 1981: input, interaction and second language acquisition. Paper presented at the New York Academy of Sciences Conference on Native and Foreign Language Acquisition.

- 1983: Native speaker/non-native speaker conversation and the negotiation of Comprehensible input. Applied Linguistics 4, 126-41.

- 1989: Task, group, and task-group interactions. University of Hawaii Working Papers in ESL 8, 1-26.

Loschky, L. and Bley-Vroman, R. 1990: Creating structure-based communication tasks for second language development. University of Hawaii Working Papers in ESL 9, 161-212.

Pica, T., Holliday, L., Lewis, N. and Morgenthaler, L. 1989: comprehensible output as an outcome of linguistic demands on the learner. Studies in Second Language Acquisition 11, 63-90.

Pica, T., Young, R. and Doughty, C. 1987: The impact of interaction on comprehension. TESOL Quarterly 21, 737-58.

Simcock, M. 1993: Developing productive vocabulary using the 'ask and answer' technique. Guidelines 15, 1-7.

Swain, M. 1985: Communicative competence: some roles of comprehensible input and comprehensible output in its development. In Gass and Madden, editors, Input in second language acquisition. Rowley, MA: Newbury House.

Ur, P. 1981: Discussions that work. Cambridge: Cambridge University Press. 


\section{Appendix: The four tasks used in the study}

\section{TASK 1: Who gets the new heart?}

\section{Situation}

You are members of a transplant team working at St Vincents hospital. There are six patients who badly need a heart transplant operation. All are critically ill and could die within a few days if they do not receive a new heart. Unfortunately there is only one heart available for the transplant and it is unlikely that other hearts will become available in the next few days.

Task

Examine the data about each patient. You must decide who should receive the next available heart. Rank the patients in order: 1 - first to receive, 6 - last to receive.

Time: You have 30 minutes to complete this exercise.

\section{The patients}

\section{Patient A}

male, 57 years old, Muslim

a heart surgeon on the point of developing a new technique in heart transplant surgery, married with two children

medical suitability: not good, likely to survive only two more years if the heart transplant is successful

\section{Patient B}

female, 38 years old, an atheist

owner of a dress shop, widow with three children, aged 4, 8 and 13

medical suitability: good

\section{Patient C}

male, 42 years old, Roman Catholic

Member of Parliament (MP), married with three children

medical suitability: not good: has had an operation for possible cancer and is quite over- . weight

\section{Patient D}

male, 18 years old, a Hindu, factory worker, single

medical suitability: good

\section{Patient E}

female, 34 years old, a Protestant

university lecturer with a PhD in chemistry

divorced and has the custody of one son aged 5 , her ex-husband is alive

medical suitability: fair, an excessive drinker and smoker

\section{Patient F}

male, 48 years old, no information on beliefs, ex-mayor of a large city, criminal record for fraud

medical suitability: good

\section{TASK 2: Redesigning a zoo}

\section{Situation}

The zoo's present layout has been causing problems. There are also some new developments. For these reasons the zoo must be rearranged.

\section{Task}

Your job is to decide what changes need to be made to the zoo using the information given below and then to rearrange the layout of the zoo. Make sure you overcome all the problems and take account of all the new developments.

Time: You have 30 minutes to finish this exercise. 


\section{Task-based interaction and incidental vocabulary learning}

\section{Information}

1) The Giraffe is about to give birth

2) One of the lions has died

3) Small children are alarmed by seeing the crocodiles facing them as they come in

4) The zoo has recently been given a new Panda

5) The monkeys are very noisy, disturbing animals

6) The camel is rather smelly

7) All the enclosures should be filled

8) Harmless animals should not be put next to predators (other animals which could attack or eat them in the natural state)

9) The zoo has enough money to buy two wolves or four flamingoes (birds) or a pair of small deer

Source: $\operatorname{Ur}(1981)$

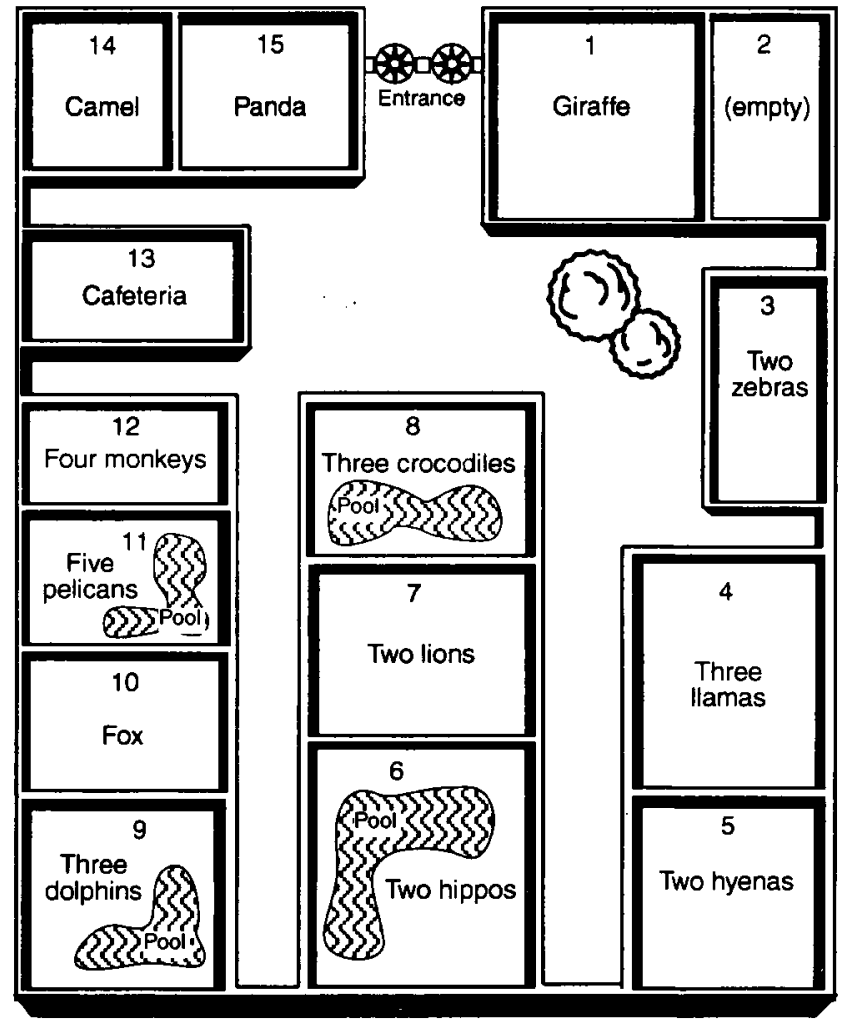

\section{TASK 3: Surgery}

Time: You have 30 minutes to complete this activity.

\section{Situation}

A new method of surgery has been discovered. This method needs four doctors to work together. Imagine you are the four doctors. Although a number of patients need this surgery, you disagree about which patient should have surgery first, second, third and fourth. 'To make 
this decision you will discuss the details of each patient together (Part 1) and then to select the most suitable patient for surgery using the criteria in Part 2.

\section{Part 1: Complete the patient records}

You have a table with some details of four patients. Other members of your group have information which is missing from your table. Ask questions to find this information and fill in the table. The order of the patients is different in each table.

Part 2: Choose the most suitable patient

Eight criteria will be used to decide which patient gets the surgery first, second, third and fourth. Each of you has two of these criteria. Tell your group your criteria and listen as they tell you their criteria. For each criterion, decide which patients are suitable and put a tick $(\checkmark)$ beside that patient. The patient with the most ticks will have surgery first.

\section{Learner $A$}

\begin{tabular}{|l|l|l|l|l|}
\hline Name & Lee, Gek Tay & & & \\
\hline Occupation & lawyer & truck driver & social worker & electrician \\
\hline Salary & & & & $\$ 29,000$ \\
\hline Qualifications & & & & Trade certificate \\
\hline Languages & 1. & 1. & 1. & 1 English \\
\hline & 2. & 2. & 2. Korean & 2. \\
\hline Marriage status & & unmarried & & \\
\hline Age & & & 34 & 42 \\
\hline Health & & high blood pressure & & \\
\hline Sports & 1. & 1. & 1. rock-climbing & 1. \\
\hline & 2. & 2. chess & 2. & 2. \\
\hline
\end{tabular}

\section{Part 2}

The most suitable patient should

1) play at least one indoor team sport and one outdoor team sport

2) be under 25 years of age if they are unmarried

The patient who will receive the surgery is $?$

\section{TASK 4: Completing a zoo plan}

Instructions: Complete this plan of a zoo by doing the following activities:

1) Share information from the plans to find out

(i) which animals are in which cages

(ii) what the other places in the zoo are called

2) Describe the symbols in your keys to find out what they represent. (The order of the symbols is not the same in each key)

3) Describe the exact position of the symbols on the zoo plans.

Time: You have 30 minutes to complete this exercise. 


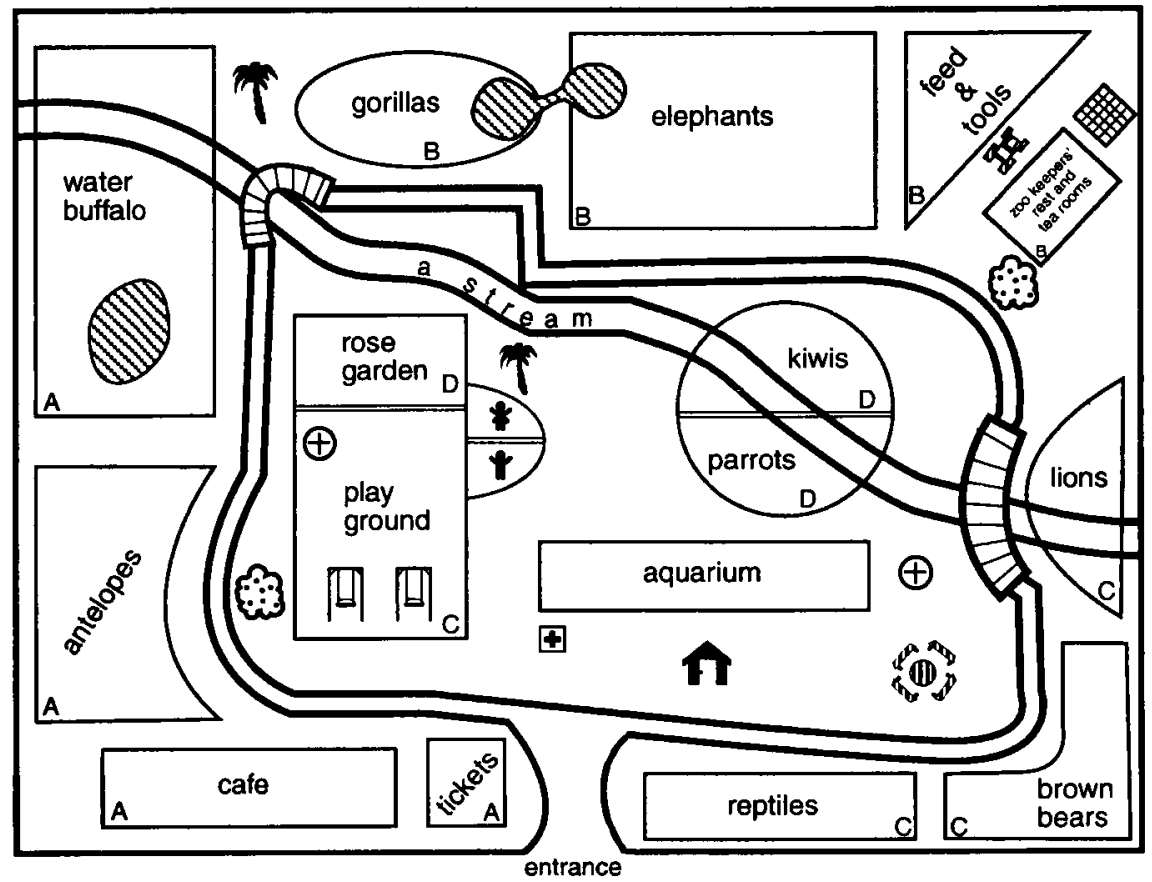

